\title{
1 Guinea worm: from Robert Leiper to eradication
}

2

3 AHMED TAYEH ${ }^{1}$

4 SANDY CAIRNCROSS ${ }^{2}$

5 FRANCIS E. G. $\mathrm{COX}^{2 *}$

6

$7 \quad{ }^{1}$ P. O. Box 127162, Dubai, UAE

$8 \quad{ }^{2}$ London School of Hygiene and Tropical Medicine, Keppel Street, London WC1E

$97 H T U K$

$10 *$ Corresponding Author

11 Tel:+44 (0)208 393 8197. E-mail: francis.cox1@ btinternet.com. Current address: 7,

12 Chessington Road, Epsom, Surrey KT17 1TS, UK.

13

14 Running title: Robert Leiper and Guinea worm eradication.

15

16

17 


\section{SUMMARY}

20 Guinea worm disease, dracunculiasis or dracontiasis, is an ancient disease with

21 records going back over 4,500 years but until the beginning of the twentieth century

22 little was known about its life cycle particularly how humans became infected. In

231905 Robert Thomas Leiper was sent by the British colonial authorities to West

24 Africa to investigate the spread of Guinea worm disease and to recommend measures

25 to prevent it. While carrying out his investigations he made important contributions

26 to the aetiology, epidemiology and public health aspects of Guinea worm disease and

27 provided definitive answers to many outstanding questions. First, he tested the

28 validity of previous theories, second, he confirmed the role of water fleas, which he 29 identified as Cyclops, as the intermediate hosts in the life cycle, third, he investigated 30 the development of the parasite in its intermediate host and, fourth, he recommended 31 measures to prevent the disease.

32

\section{3 [FOOTNOTE NEAR HERE]}

Leiper described the remarkable changes that took place when an infected copepod was placed in a dilute solution of hydrochloric acid; the copepod was 37 immediately killed but the Dracunculus larvae survived and were released into the 38 surrounding water. From this he concluded that if a person swallowed an infected copepod their gastric juice would produce similar results. He next infected monkeys by feeding them copepods infected with Guinea worm larvae and thus conclusively

41 demonstrated that humans became infected by accidentally ingesting infected 42 crustaceans. Based on these conclusions he advocated a number of control policies 
43 including avoidance of contaminated drinking water or filtering it and these 44 preventive measures paved the way for further research. The challenge to eradicate 45 Guinea worm disease was not taken up until about seven decades later since when, 46 with the support of a number of governmental and non-governmental organizations, 47 the number of cases has been reduced from an estimated 3.5 million in 1986 to 25 in 482016 with the expectation that this will eventually lead to the eradication of the 49 disease.

50

51 Key words: Robert Leiper, Dracunculus medinensis, dracunculiasis, Guinea worm 52 disease, Cyclops, copepod, disease control, safe drinking water.

53 


\section{INTRODUCTION}

56 Guinea worm disease, dracunculiasis, is one of the the oldest known human parasitic

57 diseases and has been described in the Papyrus Ebers from about $1500 \mathrm{BC}$, the 58 Bible from about $1250 \mathrm{BC}$ and in various subsequent Arabic, Persian, Greek, Roman, 59 Egyptian and other texts (See, Grove 1990 and Tayeh 1996a). The nature of the 60 infectious agent, however, remained elusive and was believed to be a vein by Persian 61 physicians who called it by a variety of names including Medina vein. The scientific 62 name, Dracunculus medinensis, incorporating the word for dragon with Medina, is 63 attributed to Bastian in 1863 (who conclusively demonstrated that it was a worm) and 64 the common name, Guinea worm, to Sir John Tennent in 1868 (See Grove, 1990 for a 65 detailed discussion of the controversy surrounding the nomenclature).

66 An association between Guinea worm disease and water had been recognised 67 since the earliest times and after the discovery of its cause controversy ranged as to 68 how the worm got from water to the human host whether by ingestion or through the 69 skin. In 1869, while looking for worms in contaminated water, the Russian 70 helminthologist, Aleksej Fedchenko, noticed that the water contained cyclopoid 71 crustaceans which he identified as Cyclops sp. and, when he dissected them, found 72 that they harboured larval worms that he suspected might be the intermediate stages 73 of the Guinea worm and postulated that humans became infected by accidentally 74 ingesting the crustacean in drinking water (Fedchenko, 1870). Other eminent 75 scientists began to investigate this possible mode of transmission and the German 76 helminthologist Rudolf Leuckart, probably the leading helminthologist at that time, 77 suggested that Fedchenko should investigate the development of the worm in 78 copepod crustaceans based on the similarity of the first stage larvae to those of 
79 Cucullanus elegans, the life cycle of which he, Leuckart, had already determined.

80 Fedchenko, however, failed to demonstrate the complete life cycle as cats and dogs

81 fed infected copepods did not become infected. Other scientists doubted his theory

82 and also failed to complete the life cycle so Fedchenko's theory was largely

83 abandoned. It is against this background that Leiper began his ground-breaking

84 research into dracunculiasis

85

86

LEIPER'S MISSION TO WEST AFRICA

87 Early in the twentieth century Guinea worm disease had become recognised as a

88 serious problem in terms of incidence and severity in the main towns of the Gold

89 Coast (now Ghana) and Nigeria particularly as it affected British troops and the 90 health of the labour force with consequences for political stability and the economy

91 of these colonies. The British colonial administration required action in order to 92 determine the mode of transmission of the disease and measures to control it. Thus 93 the Committee of the London School of Tropical Medicine asked Robert Thomas 94 Leiper, in 1905, to go to Accra in the Gold Coast (now Sierra Leone) West Africa 95 charged with finding ways to control the disease.

96 Leiper had been appointed by Patrick Manson as helminhologist at the

97 London School of Tropical Medicine in 1905 at the age of 24 (Cox, 2017). He had 98 only recently graduated in medicine with no tropical experience and little or no 99 training in scientific methodology and only one publication on a turbellarian worm 100 from a sea urchin (Leiper, 1904). Nevertherless, in 1905 with Manson's support, 101 Leiper departed to West Africa to undertake this assignment. 102 
104 and how it might be controlled. Leiper was aware that Fedchenko had shown that

105 copepods were the intermediate hosts of D. medinensis, and had correctly surmised

106 how humans become infected with the parasite, but that he and other scientists had

107 failed to complete the life cycle. Leiper took up this task with enthusiasm and

108 vigour. Leiper's experiments and observations were to become classics and set 109 standards that persist to the present time.

\section{Dismissing existing theories and confirming others}

112 Leiper began by reviewing all the prevalent conflicting hypotheses: (1) that the

113 development of the embryos can be completed without the intervention of an 114 intermediate or second host or (2) that development in the intermediate host is 115 essential for the larva to be able to re-infect man. Under each of these hypotheses,

116 Leiper listed several theories that had been promoted at that time. He dismissed the 117 first category and provided experimental evidence that the embryos cannot infect 118 humans directly via the skin or mouth until after they had undergone further 119 development in the copepod intermediate host (Leiper, 1907). In order to demonstrate that infection was due to the ingestion of infected

121 crustaceans he fed a monkey on bananas containing copepods that had been infected

122 for five weeks and which contained apparently mature larvae. Six months later, a 123 careful post-mortem examination of the monkey revealed the presence in the 124 connective tissues of five worms that possessed the anatomical characteristics of 125 Dracunculus medinensis (Leiper, 1906a; 1907). In order to demonstrate the absence 126 of a second intermediary host, Leiper referred to his work in Nigeria in which he 
127 found that the only organism in the ponds that could cause infection were infected 128 copepods (Leiper, 1907).

130 The behaviour of embryos in water

131 Leiper then observed that Dracunculus embryos can survive in water for three days

132 and some for six days. He did not specify the temperature of the water but noticed 133 that the larvae stayed alive a day or two longer in mud, probably by saving energy 134 while dormant. Dracunculus embryos are unable to obtain food in water although 135 they have a mouth and a digestive tract and must find a suitable crustacean within a 136 few days and must be able to enter the body cavity of the crustacean host. Leiper 137 observed that the embryos are frail and can die quickly if dried by evaporation but 138 can't be revived by adding water (Leiper, 1907).

\section{Behaviour and metamorphosis of the embryo in copepod crustaceans}

141 Leiper observed that the mode of entry of the embryo is through the intestine of the

142 copepod and not through the integument as previously believed and that the larvae 143 showed no tendency to leave the crustacean host and become free-swimming. As 144 time went on, the larvae became inactive, and when the crustaceans died, the larvae 145 also died. Two days after emergence, the larvae lost their very delicate enveloping 146 pellicle and thereafter development ceased. Further changes were only in the

147 differentiation of internal structures and the larvae finally became mature on the fifth 148 day and that the striate cuticle was cast on the eighth day (Leiper, 1907).

150 Behaviour of Dracunculus larvae and copepods in hydrochloric acid solution 
151 Leiper's next investigation was to mimic the conditions in the human stomach. He 152 observed and described in detail how the copepods containing the Dracunculus 153 larvae behave when placed in a drop of water together with 0.2 per cent hydrochloric 154 acid, representing the acidity of the gastric juice in the stomach (Leiper, 1906b).

155 Although the copepods died the larvae regained their former activity, at first slowly, 156 but gradually with increasing strength and speed, and burst into the body cavity of the 157 dead crustacean. Eventually, the young worms reached the water and there swam 158 with great speed. In a control experiment, copepods containing embryos of the same 159 date of infection and in all respects similar to those used in the experiment but to 160 which no acid had been added remained alive for a further period of two weeks but 161 the larvae they contained did not exhibit any changes. Some copepods died, but the 162 larvae did not try to escape and died as well.

163

164 From all these experiments and observations, Leiper concluded that

165 'The young (larvae) must be discharged directly into fresh water soon after 166 the parent worm has succeeded in creating a break in the overlying skin and before the wound has become markedly septic. The embryos must find a cyclops within a few days. They must, moreover, succeed in entering its body cavity. Five weeks later they will have developed into mature larvae. They must, therefore, be taken into a human stomach, and having been set free from their host by the gastric juice, reach the connective tissues by penetrating the gut wall' (Leiper, 1907).

173

174

175 Leiper made another important discovery when he found two males each $22 \mathrm{~mm}$ long

176 in an experimentally infected monkey and commented on the importance of the 
177 discovery of the male and immature female forms in the connective tissues, thus

178 showing that the life cycle of Guinea worm was in accord with what was known of

179 the after-development of other filarial parasites (Leiper, 1906a). Thus, in a very short

180 period of time, Leiper had completed our knowledge of the life cycle of Dracunculus

181 medinensis. He also made several recommendations for future research. These

182 included: to explore the conditions under which the intermediate host (Cyclops) lives

183 and multiplies in tropical settings; to ascertain the natural enemies and the food

184 supply of the Cyclops; to observe whether Cyclops can survive the summer drought;

185 to experiment and explore whether by adding chemicals, Cyclops could be destroyed

186 in suspected water without risking human health. In the same paper Leiper also set

187 out very clearly his prognosis for Guinea worm disease.

188 'It is evident that dracontiasis will disappear from the Gold Coast towns with 189 the provision of properly-controlled water supply obtained either from 190 artesian wells or through pipes from rapidly-flowing streams.' (Leiper, 1907).

191 Later, Leiper (1936) stressed the need for regional surveys of crustaceans as 192 important intermediate hosts in the spread of human disease.

194 Seasonality of infection

195 Leiper believed that knowing the season of infection was very important for the 196 success of preventive measures in that area. As far as we know, Leiper was the first 197 scientist to compare the seasonal incidence of Guinea worm with the monthly rainfall 198 (Leiper, 1911a). He was fortunate that there were rainfall data from 1891 to 1894 in 199 the Gold Coast as well as Guinea worm incidence data during the same period that 200 enabled him to draw such tables. The life cycle of D. medinensis is one year and, 201 although he did not compare the rainfall in one year (risk factor) and new cases in the 
202 following year (infection), as is done nowadays (Cairncross et.al. 2002), he did show 203 that rainfall in the years 1891 to 1894 was consistent in its seasonality. The highest 204 peak occurred between April and May with a smaller peak in October-November. 205 Later, scientists developed this method by plotting worm emergence (the infection) in 206 one year with the rainfall one year earlier since the incubation period is 207 approximately one year.

208 Leiper observed that in the Gold Coast there are different periods for wet and 209 dry seasons: (1) A long dry season, November-March, (2) A long wet season, April210 June, (3) A short dry season, July-September, and (4) A short wet season, October 211 and November. He recommended the use of artesian wells or pipes from rapidly 212 flowing streams for provision of drinking water during the dry seasons, which is the season of infection in Ghana, and also the filling in of surface water and shallow 214 wells.

Leiper's discoveries in summary

217 By 1907 Leiper had established that Guinea worm disease is acquired by 218 drinking water containing copepods infected with larval Dracunculus medinensis.

219 When in the stomach of the mammalian host the crustacean is killed by stomach acid, 220 the larvae emerge and migrate to connective tissue where they mature and mate and, 221 one year later, the mature female worm full of embryos emerges, usually from the leg 222 The larvae are ingested by the copepod, moult and develop to become infective and 223 the life cycle is completed when a person drinks water containing the infective 224 crustaceans (Muller, 1971). 
227 The main objective of Leiper's trip to West Africa in 1905 was to study the aetiology

228 of Guinea worm disease with a view to recommending ways to control it. He 229 suggested that infective individuals should be prevented from coming into contact 230 with infected and uninfected copepods and that this should be the aim of any 231 organized effort to control the disease. Thus for West Africa he recommended the 232 avoidance of contaminated water and the provision of safe drinking water during the season of infection. Leiper subsequently visited India and recommended replacing

234 step wells, where people descend down a series of steps to collect water directly from 235 the source, with draw wells where people collect water in buckets and therefore do 236 not come in direct contact with any water. He also recommended building high 237 parapets around the mouths of wells to prevent people from wading into the water 238 and to prevent the return of spilled water. To kill the adult copepods in well water, he 239 suggested raising the temperature of the water in the well, suddenly, by passing steam 240 through it from a mobile boiler (Leiper, 1911b). He was aware that this method might 241 not prove practical, but taking into consideration that the disease was seasonal, it 242 would only have to be done during the transmission season. Most importantly, Leiper 243 was careful to indicate that any preventive measures should be simple and 244 inexpensive and should take into account the climate, people's behaviour and 245 different drinking water sources. Leiper made one more important suggestion for the 246 possible control of Guinea worm disease when he revisited West Africa in 1912 and 247 observed that the disease was absent in places where there were fish living in the 248 water sources and suggested that this might be a method of controlling the disease 249 (Leiper, 1913). Apart from this one paper and a review in 1936 (Leiper, 1936) Leiper 250 never returned to the study of Guinea worm disease and by 1908 he had turned his 
attention to hookworms and later schistosomiasis, the work for which he is best

252 known (see Stothard et al., 2017).

253

\section{FOLLOW UP STUDIES BY OTHER SCIENTISTS}

255 Leiper can be credited for his extensive work that revived scientific interest in Guinea 256 worm disease and paved the way for further research by other scientists while he 257 continued his work on other diseases such as schistosomiasis. The most important 258 work on the biology of Guinea worm disease conducted during subsequent decades 259 has been reviewed by Muller (1971) and Cairncross et al. (2002). Scientists who 260 continued Fedchenko and Leiper's work on the natural history of the disease include 261 Onabamiro (1950), Moorthy (1938), Roubaud (1918) and others who have 262 investigated the different stages of development of the larval worms. It was, however, 263 some 50 years after Leiper's expedition to West Africa that several authors, 264 including Muller (1968, 1971), repeated his work on the effect of gastric acid on 265 infected copepods and the aetiology of the disease (Cairncross, et al. 2002). These 266 later studies did not challenge Leiper's results but confirmed and added further 267 details regarding the behaviour of the parasite and intermediate host under different 268 conditions including temperature. Other researchers have continued the work of 269 Leiper in evaluating different preventive measures to control and eventually to 270 eradicate the disease. This possibility was first mooted by Leiper in 1907 although he 271 could not have imagined that the incidence of Guinea worm disease would decline 272 almost to vanishing point 110 years later.

273

274 CONTROL AND ERADICATION OF GUINEA WORM DISEASE 
275 Despite Leiper's discoveries and recommendations, Guinea worm remained a 276 neglected disease for over seventy years and authorities in endemic countries gave its 277 control little priority probably because it mainly affected people living in rural and 278 remote areas, far from urban centres. The first major intervention supported by a 279 government to eradicate the disease was achieved in the former Soviet Union 280 between 1923-1931 by the Tropical Institute in Bukhara with the aim of eliminating the disease from the city and eight other permanently-inhabited areas nearby, the only remaining foci of infection in the USSR (Now Uzbekistan) at that time. Various measures of prevention were employed including protecting the water sources, 284 draining ponds, cleaning water sources and treating them with chemicals. In addition 285 dogs suspected of infection with dracunculiasis were destroyed. The most crucial factor in eliminating the disease was the construction of a safe water supply system in 287 Bukhara in 1929. The last indigenous case of human dracunculiasis in the country was reported in 1931 (Litvinov, 1991).

Meanwhile, in several other endemic countries, the disease disappeared, not 290 by deliberate eradication campaigns but by the provision of safe drinking water. By the early 1970s, for example, most areas of Saudi Arabia had piped water systems. In rural areas of Iran burkah (traditional water storage cisterns) were treated with insecticides for malaria control and although these measures failed to eradicate 294 malaria, they had the incidental side effect of eliminating dracunculiasis (P. Ranque 295 personal communication, Tayeh, 1996b).

Apart from these sporadic initiatives, Guinea worm disease remained 297 virtually neglected until 1980 when a number of counties, mainly in Africa, realised 298 that it was a serious health problem and that a coordinated international campaign to 299 eradicate the disease was necessary and urgent action was required. The challenge of 
eradicating Guinea worm disease was taken up by the American Centers for Disease

301 Control and Prevention, Atlanta, Georgia (CDC) (Hopkins and Foege, 1981). The

302 United Nations Development Programme (UNDP) subsequently added Guinea worm

303 to the United Nations International Drinking Water Supply and Sanitation Decade

304 1981-1990 (IDWSSD). Guinea worm disease featured in this initiative mainly

305 because the disease could only be transmitted through drinking contaminated water and any success in reducing the incidence of or eliminating the disease could be used

307 as an indicator of success in providing safe drinking water. A major breakthrough 308 occurred in 1986, at which time Guinea worm disease was endemic in twenty 309 countries mainly in Africa, with an estimated 3.5 million cases. In 1986 The World 310 Health Organization, somewhat belatedly, formally supported a campaign for the 311 eradication of the disease. A key role in the campaign was played by the Carter

312 Center. The Center, established in 1982 with the twin aims of Resolving Political 313 Conflict and Combating Disease, had been the brainchild of the former United States

314 President, Jimmy Carter (President 1977-1981). Carter had a personal interest in 315 Guinea worm disease having witnessed its devastating effects during a trip to West 316 Africa with his wife in the early 1980s. His interest never waned and he made 317 several other trips to endemic areas during the 1980s. In 1986, this initiative became 318 the Guinea Worm Eradication Programme (GWEP) the ambitious aim of which was 319 the global eradication of Guinea worm disease. This was to involve the participation 320 of the health service in the endemic countries with financial support from various organizations including the Department for International Development UK (DFID),

322 NGOs and hundreds of other donors including the Bill \& Melinda Gates Foundation

323 largely channelled through The Carter Center. The approach was simple, the 324 provision of safe drinking water sources, community-based projects such as building 
325 protective walls around wells and other water sources to prevent people coming in to 326 contact with contaminated water, the provision of fine-mesh cloth filters for

327 households without access to safe water, and the treatment of water sources with 328 chemical larvicides such as Temephos (Abate). At the personal level, individuals 329 were provided with cloth filters and, later, pipe filters, plastic tubes with a nylon filter 330 to remove the crustaceans and through which they could drink possibly contaminated 331 water safely. Despite a number of missed targets due to logistical difficulties and 332 lack of human, financial and technical resources (Cairncross et al, 2012) coupled 333 with local and international conflicts and population movements, progress towards 334 the eradication of Guinea worm disease was spectacular and by 1990 the number of 335 reported cases had fallen from an estimated 3.5 million in 20 countries to 892,055 in 33616 countries. Thereafter there was steady progress and at the end of 2015 there were 337 only 22 cases in four countries, Chad, Ethiopia, Mali and South Sudan. (WHO, 2015) 338 (See Figure 1).

340 [FIGURE 1 NEAR HERE] Since then, Mali has been declared free from Guinea worm disease and in 343 January 2017 there were 25 cases reported during 2016 in the remaining three 344 countries (GW Wrap Up, No. 242, 2016). The WHO has published a detailed time 345 line showing the progress of the eradication programme until 2013 (WHO, 2015). 346 Jimmy Carter has remained in the forefront of these campaigns and in 2015 stated 347 that he hoped to live long enough to witness the last case of Guinea worm disease 348 (Geggel, 2015). Currently, tremendous efforts and resources are being invested in 349 order to trace and stop the few remaining cases from transmitting the disease. One 
problem here is that the infected individuals must have become infected a year earlier and tracing backwards is labour intensive and expensive.

\section{THE DOG THAT DIDN'T BARK}

354 One of Leiper's lesser observations was that Dracunculus medinensis occurred in 355 wild and domesticated animals (Leiper, 1910). Since then it has been reported sporadically in apes, cats, dogs, foxes, wolves, leopards, jackals, horses and cattle (see Muller, 1971) but, somewhat surprisingly, this information has not been well

358 disseminated and does not appear in standard works on Zoonoses such as Palmer et

$359 a l ., 2011$. Leiper must have been aware that dogs were susceptible to infection when

360 he tried to infect them with infected crustaceans but no one suspected that they might act as reservoirs of human infection partly because it was thought that the species in

362 animals was different from that in humans or that dogs acquired their infections from

363 humans and not vice versa. In 2015, however, 459 dogs in 150 villages in Chad were

364 found to be infected with the human form of D. medinensis confirmed by genome sequencing (Eberhard et al., 2014). It is not known how this might threaten the

366 Guinea worm eradication programme but the authorities in Chad are taking no

367 chances. Sources of infection in dogs include fish that had ingested infected copepods

368 so villagers have been encouraged to bury or to otherwise destroy the remains of fish

369 and fish entrails. Villagers have also been encouraged to report infected dogs with a

370 reward of US\$20 to those that do so, tethering of infected dogs and treatment of 371 drinking water used by dogs with Abate. This illustrates the extreme measures that 372 authorities are taking to eradicate Guinea worm disease. In Uzbekistan in the 1920s, 373 control measures included shooting and dissection of dogs but this may not be 374 acceptable or feasible under all circumstances. With continued efforts and goodwill it 
375 is very likely that Guinea worm disease will be eradicated within the next year or two 376 and will join smallpox as the second human disease to be wiped from the face of the 377 earth. Robert Leiper died in 1969, well before anyone had seriously considered the 378 possibility of the global eradication of Guinea worm disease. When they did, the idea 379 was largely based on his pioneering work carried out over a century before.

\section{FINANCIAL SUPPORT}

382 This research received no specific grant from any funding agency, commercial or not383 for-profit sectors.

DECLARATION OF INTERESTS.

386 No interests declared.

\section{REFERENCES}

389 Cairncross, S., Muller, R. and Zagaria, N. (2002). Dracunculiasis (Guinea worm 390 disease) and the eradication initiative. Clinical Microbiology Reviews, 15, 223-246.

391 Cairncross, S, Tayeh, A. and Korkor, A. S. (2012). Why is dracunculiasis

392 eradication taking so long? Trends in Parasitology, 28, 225-230.

393 Cox, F.E G . (2017). Robert Leiper and the London School of (Hygiene and)

394 Tropical Medicine. Parasitology, xxx, xxx-xxx.

395 Eberhard, M. L., Ruiz-Tiben, E., Hopkins, D. R., Farrell, C., Toe F., Weiss, A., 396 Withers, P. C. Jr, Jenks, M. H., Thiele, E. A., Cotton, J. A., Hance, Z., Holroyd, 397 N, Cama, V,A., Tahir, M.A. and Mounda, T. (2014). The peculiar epidemiology of 398 dracunculiasis in Chad. American Journal of Tropical Medicine and Hygiene, 90, $399 \quad 61-70$. 
400 Fedchenko, A. P. (1870). Concerning the structure and reproduction of the Guinea 401 worm (Filaria medinensis). In Russian. Translation: American Journal of Tropical 402 Medicine and Hygiene, 20, 511-523. 1971.

403 Geggel, L. (2015). Life Science September 1, 2015. Life Science Publishing, Calgary 404 Canada.

405 Grove, D. I. (1990). A History of Human Helminthology. C.A.B. Wallingford, UK. 406 GW Wrap Up (2016). Guinea Worm Wrap-Up No. 245. WHO Collaborating Center 407 for Research, Training and Eradication of Dracunculiasis. Centres for Disease 408 Control and Prevention, Atlanta, Georgia, USA. .

409 Hopkins, D. R. and Foege, W. H. (1981). Guinea worm disease. Science, 212, 495.

410 Leiper, R .T. (1904). On the turbellarian worm Avagina incola, with a note on the 411 classification of Proporidae. Proceedings of the Zoological Society of London, 1, 1-7.

412 Leiper, R .T. (1906a). Some results of the infection of monkeys with Guinea worm.

413 Report of the British Association for the Advancement of Science, 76, 600.

414 Leiper, R. T. (1906b). The influence of acid on Guinea worm larvae encysted in 415 Cyclops. British Medical Journal, 1, 19-20.

416 Leiper, R. T. (1907). The aetiology and prophylaxis of dracontiasis. British Medical 417 Journal, 1, 129-132.

418 Leiper, R. T. (1910). Guinea worm in domesticated animals with a note of its 419 discovery by Mr Charles Grey in a leopard. Journal of Tropical Medicine and 420 Hygiene, 13, 65-66.

421 Leiper, R . T. (1911a). A method for dealing with town wells infected with Guinea 422 worm. Journal of the London School of Tropical Medicine, 1, 28-30.

423 Leiper, R. T. (1911b). Note on the seasonal incidence of dracontiasis in the gold 424 coast. Journal of Tropical Medicine and Hygiene, 14, 211-212. 
425 Leiper, R. T. (1913). Seven helminthological notes. A. The occurrence of Guinea

426 worm in Nyasaland. Journal of the London School of Tropical Medicine, 2, 175.

427 Leiper, R . T. (1936). Crustacea as helminth intermediates. Proceedings of the Royal 428 Society of Medicine, 29, 9.

429 Litvinov, S. K. (1991). How the USSR rid itself of dracunculiasis. World Health 430 Forum, 12, 217-219.

431 Moorthy, V. N. (1938). Observations on the development of Dracunculus 432 medinensis larvae in Cyclops. American Journal of Hygiene, 27, 437-465.

433 Muller, R. (1968). Studies on Dracunculus medinensis (Linnaeus). I. The early 434 migration route in experimentally infected dogs. Journal of Hygiene, 42, 331-338.

435 Muller, R. (1971). Dracunculus and dracunculiasis. Advances in Parasitology, 9, 73436151.

437 Onabamiro, S. D. (1950). The transmission of Dracunculus medinensis by 438 Thermocyclops nigerianus as observed in a village in South-West Nigeria. Annals of 439 Tropical Medicine and Parasitology, 45, 1-10.

440 Palmer, S. R., Soulsby, L., Torgenson, P. R. and Brown, D. W. G. eds. (2011). 441 Oxford Textbook of Zoonoses. Oxford University Press, Oxford, UK.

442 Roubaud, E. (1918). Discussion of Chatton on infection of Cyclops through

443 digestive tract. Bulletin de la Société de Pathologie Exotique, 11, 347-348.

444 Stothard, J. R., Kabatereine, N. B., Archer. J., Shehri, H. Al-, Tchuem-Tchuenté 445 L. A, Gyapong, M. and Bustinduy, A. L. (2017). A century of Robert T. Leiper's 446 lasting legacy on Schistosomiasis and a COUNTDOWN on control of neglected 447 tropical diseases. Parasitology, xx, xxx-xxx. 
448 Tayeh, A. T. (1996a). Dracunculiasis. In The Wellcome Trust Illustrated History of

449 Tropical Diseases, (ed.Cox, F. E. G.), pp. 287-293. The Wellcome Trust, London, 450 UK.

451 Tayeh, A.T. (1996b). Eradication of Dracunculiasis in the Islamic Republic of Iran.

452 Country Report prepared by the Directorate General Disease Prevention and

453 Surveillance. Ministry of Health and Medical Education, Islamic Republic of Iran.

454 World Health Organization (2015). Eradication of Dracunculiasis: A Handbook for

455 International Certification Teams.WHO Geneva, Switzerland.

456

457

458

459

460

461

462

463

464

465

466

467

468

469

470

471

472

473 
474 FOOTNOTE.

475 The crustacean Order Cyclopoida in the Family Cyclopidae contains 25 genera including

476 Cyclops which itself contains over 400 species and may not even be a valid taxon. It is not

477 known how many of these species (or indeed species belonging to related genera) can act as

478 intermediate hosts of Dracunculus medinensis nor do we know which species Fedchenko,

479 Leiper and other workers used in their experiments. It is, therefore, best to use the terms

480 copepod, or copopoid crustacean rather than Cyclops in scientific texts. In this paper these

481 crustaceans are referred to as copepods except when referring $\mathrm{g}$ to an original text.

482

483

484 Figure 1. Annual number of cases of Guinea worm disease 1989-2015.

485 